\title{
Design study for a multi-component transducer for wind turbine test benches
}

\author{
Jonas Gnauert ${ }^{1}$, Georg Jacobs ${ }^{1}$, Stefan Kock ${ }^{1}$, Dennis Bosse ${ }^{1}$, Benjamin Janik ${ }^{1}$ \\ ${ }^{1}$ Chair for Wind Power Drives, Campus-Boulevard 61, 52074 Aachen, Deutschland
}

\begin{abstract}
This paper covers the design study of a multi-component transducer (MCT) for wind turbine test benches. The MCT will cover the characteristics of wind turbines in the performance class up to $6 \mathrm{MW}$. The motivation to develop such a MCT is to provide a satisfying accuracy in measurement of loads and moments in all six degrees of freedom, to reduce the uncertainty in the traceability of the drive train behavior due to the applied loads. Therefore, the estimation of the measurement uncertainty is significant to evaluate the design of the MCT. At the beginning, the design process of the MCT is shortly introduced. Afterwards, the strain gauges based transducer design is investigated under operational conditions (e.g. torque, and multiaxial loads) by using FE simulations to determine the crosstalk effects. Finally, the measurement uncertainties of all measurements are determined based on these FE simulations according to the type B evaluation of the GUM [1], including metrological aspects (e. g. linearity deviation and hysteresis) and the crosstalk. It can be shown that the MCT provides a high potential to significantly improve the measurement uncertainty of the applied wind loads on a wind turbine test bench.
\end{abstract}

Keywords: mechanical measure, multi-component transducer, wind turbine test bench, measurement uncertainty, design study

\section{Introduction}

Wind industry is a major pillar of climate-friendly energy supply in Germany. The wind industry supplies $17.2 \%$ of the energy production, which sums up to $49.2 \%$ of the renewable resources (Germany 2018) [2]. To ensure that wind industry keeps expanding and becomes competitive to fossil and nuclear sources wind turbines must be further optimized concerning availability and reliability [3]. Wind turbine test benches (TB) are crucial to face these aims. A conventional TB comprises a Prime Mover for torque generation on the Main Shaft, Load Application System for the application of wind forces and bending moments, Device under Test and Electrical Power Supply Equipment, e.g. converter, transformer, and filters, see Fig. 1. The existing TB [4], compared to default field tests, provide the opportunity to investigate the behavior of the entire drive train and control system under free adjustable, controlled and reproducible operating conditions. Thereby it is possible to apply simultaneously multiaxial dynamic wind loads as well as highly fluctuating electrical grid loads on the wind turbine, to simulate a realistic field load situation. With the 4 MW RWTH nacelle test bench, it is possible to apply $3.4 \mathrm{MN} \cdot \mathrm{m}$ torque under maximum bending moments of about $7 \mathrm{MN} \cdot \mathrm{m}, 3.3 \mathrm{MN}$ radial forces and 4.0 $\mathrm{MN}$ thrust [5].

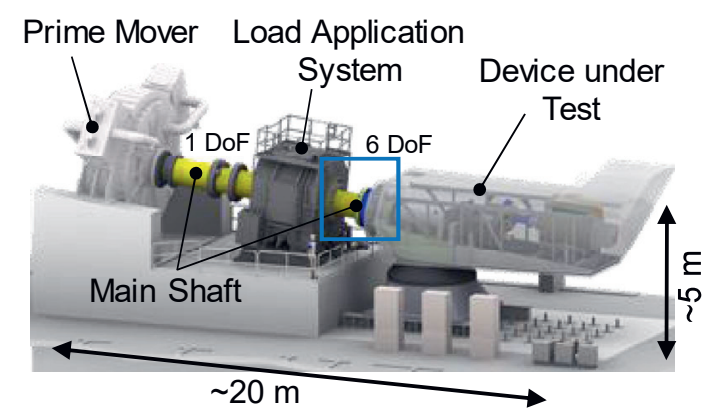

Fig. 1 4MW RWTH Wind Turbine Test Bench [5] - Main components

The exact knowledge of the applied wind loads on a TB is thereby necessary for the [6]:

- Determination of the wind turbine efficiency,

- validation of simulation models as well as

- characterization of the drive train behavior under critical operation modes.

Today the applied wind loads in WT can be determined just imprecise, for example: the wind loads are calculated by the measurement of the hydraulic pressure in the hydraulic cylinders of the Load Application System. This method neglects for instance the speed- 
dependent friction inside the cylinders. A multicomponent transducer (MCT), which is directly implemented in the power transmission between the Load Application System and the Device under Test, would solve this issue. Therefore, a MCT, which is capable of a precise measuring of all six degrees of freedom simultaneously (DoF) under rotation, is required to improve the traceability of the applied wind loads. Until now, there are no commercial MCT for this dynamic and high load application available. This paper intends to introduce a design study of such a MCT for TB.

\section{Design Study}

A MCT between the load application system and the device under test on a TB shows a high potential to reduce the uncertainty in the traceability of the drive train behavior due to the applied loads. For this reason, a design study is carried out to identify a suitable transducer design. The design study is executed according to the design methodology of the VDI 2221 [7]. The design methodology divides the design process into four different steps:

- Classification of the Task,

- Conceptual Design,

- Embodiment Design and

- Detail Design.

This design study is focusing on the first three steps (see Fig. 2). First, the requirements for a MCT are identified and a various conceptual designs are developed. Based on a multicriteria decision analysis the most suitable design concept is selected and a strain gauges based transducer is designed.

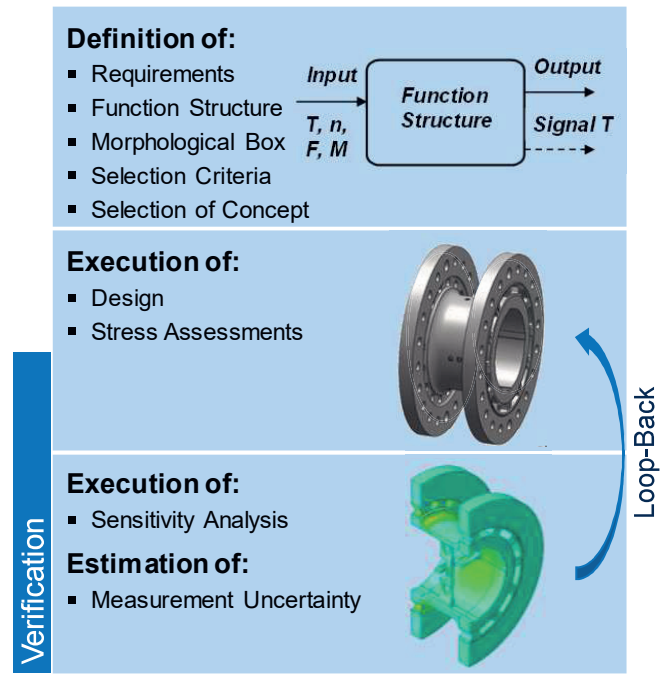

Fig. 2 Approach of the Design Study of the $M C T$

For this design a sensitivity analysis with Finite Element simulations are executed to improve the geometry concerning the load capacity, measurement range and to reduce crosstalk between the measuring points under operating loads (e.g. torque, and multiaxial loads). Finally, the measurement uncertainty for each measurement is estimated, taking the crosstalk and the metrology characteristics for strain gauges like e.g. linearity, hysteresis and repeatability into account.

\section{Classification of the Task}

For the design study, the characteristics of wind turbines in the performance class up to $6 \mathrm{MW}$ are considered for the requirements. By consideration of this performance class, the following nominal measurement ranges arise:
- Axial force
$1,5 \mathrm{MN}$
- Lateral force
$2 \mathrm{MN}$
- Bending moments
$5 \mathrm{MN} \cdot \mathrm{m}$
- Torque
$5 \mathrm{MN} \cdot \mathrm{m}$

To achieve a precise measuring with a high sensitivity for all DoF, an individually design of the measurement ranges are necessary. Besides the individually design of the measurement ranges the crosstalk between the measuring points must be minimized. Additionally, the MCT must fulfill also these general requirements, which are:

- Each measurement uncertainty: <1\% referred to measured value,

- Operation conditions e.g. maximum rotational speed of $30 \mathrm{rpm}$,

- Ambient conditions: maximum temperature of $45^{\circ} \mathrm{C}$

- Dimensional conditions: max diameter of $4,5 \mathrm{~m}$ and max length of $2 \mathrm{~m}$

Based on these requirements design concepts were identified in the next design phase.

\section{Conceptual Design}

In the Conceptual Design phase, a function structure of the MCT is developed. The function structure identifies all the necessary function, which must be fulfilled to reach the requirements. Starting from the main function "Measurement of all six DoF", the structure is further divided into the main sub-functions of the measurement of each DoF. Every main subfunction is furthermore divided into the subfunction of:

- Separation of the measure

- Conversion of the measure

- Creating of the measuring signal

- Compensation of disturbance variables

- Transfer of measuring signal

For each sub-function various principles were developed, which combined are capable of solving the main function "Measurement of all six DoF". With these design principles, different 
design concepts were generated and with the help of a multi-criteria decision analysis (weighted sum model) compared. The most suitable design concept is selected (see Fig. 4) for further investigations.

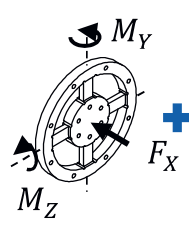

Axial Force and Bending Element

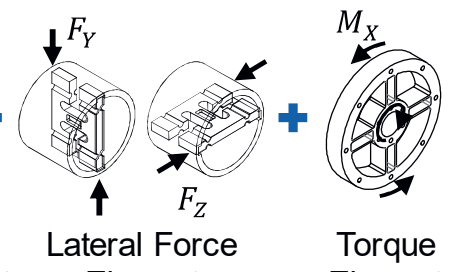
Element

Element

\section{Fig. 3 Selected design concept for the MCT}

\section{Embodiment Design}

Starting from the selected design concept the Embodiment Design of the MCT is designed. The Embodiment Design of the MCT can be seen in Fig. 5. The measuring body of the MCT consists of three main elements:

- Lateral Force Elements,

- Torque Element as well as the

- Axial Force and Bending element.

Strain gauges are installed on the elements to measure the strain resulting from the input loads. The strain gauges are connected in Wheatstone bridges. The separation of the single sub-functions in individual elements ensure the possibility to design the measurement ranges independent. This allows an optimization of the measuring points concerning to the sensitivity and crosstalk.

To achieve these optimizations a FE model of the MCT is build up. The strain gauges are modelled with the Spring method according to [8] and the Wheatstone bridges are considered afterwards with an analytical approach. With the help of this FE model, the geometry was optimized concerning the load capacity, measurement range and crosstalk reduction between the measuring points under operating loads: axial load, lateral load, bending moment and torque (see Fig. 6).

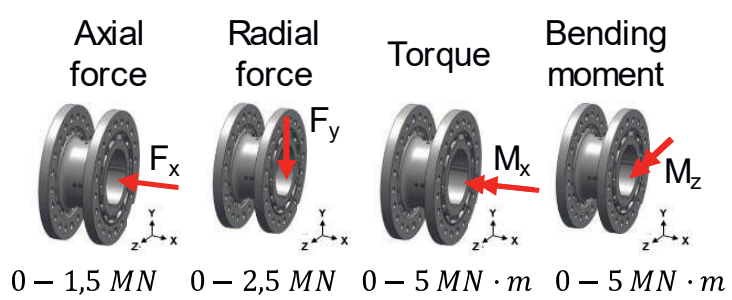

\section{Fig. 5 Operational conditions}

Therefore, the operating loads were applied on the MCT and the signal of each Wheatstone bridge was calculated depending on the simulated strains and the analytic behind each Wheatstone bridge. By this, it is possible to determine the nominal output signals depending on each nominal load and the amount of crosstalk from another load on an output signal. To reduce the crosstalk an iteration process (see Fig. 7) was used, which made it possible for example to reduce the crosstalk of bending moment to the lateral force element from $2.68 \%$ to $0.61 \%$.

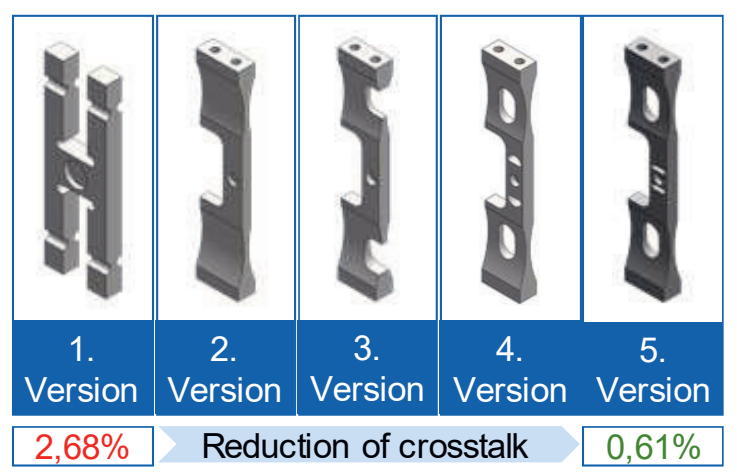

Fig. 6 Reduction of Crosstalk thru an iteration process (Loop Back)

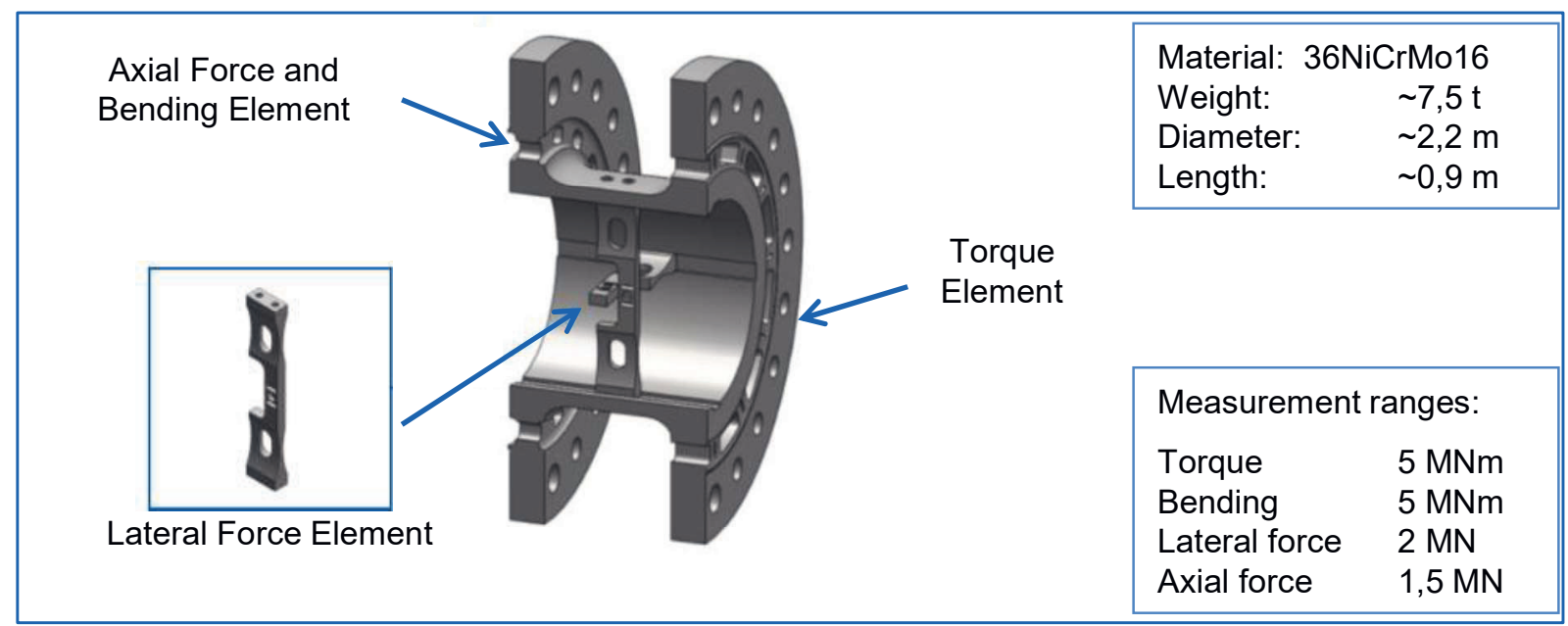

Fig. 4 Developed design of a MCT for TB 
The remaining crosstalk in the MCT is summarized in Tab. 1. By knowing the crosstalk and the metrology characteristics for strain gauges like e.g. linearity, hysteresis and repeatability it is possible to estimate the measurement uncertainty of each measurement.

Tab. 1: $\quad$ Crosstalk of each nominal load $F_{n o m, j}$ on the nominal output signal $S_{j}$ of each measurement and the combined crosstalk $d_{\text {talk }}$

\begin{tabular}{|c|c|c|c|c|}
\hline & $\begin{array}{c}S_{F x} \\
{[\%]}\end{array}$ & $\begin{array}{c}S_{F y} \\
{[\%]}\end{array}$ & $\begin{array}{c}S_{M x} \\
{[\%]}\end{array}$ & $\begin{array}{c}S_{M z} \\
{[\%]}\end{array}$ \\
\hline$F_{x}$ & - & 0,052 & 0,000 & 0,002 \\
\hline$F_{y}$ & 0,004 & - & 0,001 & 0,447 \\
\hline$M_{x}$ & 0,016 & 0,608 & 0,002 & - \\
\hline$M_{z}$ & 0,003 & 0,003 & - & 0,011 \\
\hline \hline$d_{\text {talk }}$ & 0,023 & 0,663 & 0,003 & 0,460 \\
\hline
\end{tabular}

Estimation of the measurement uncertainty

The estimation of the measurement uncertainty for the MCT is performed according to the "Guide to the Expression of Uncertainty in Measurement" (GUM) [1]. For the estimated measurement uncertainty, it is assumed that the MCT will be calibrated according to metrological standards.

To estimate the measurement uncertainty, a mathematical model for each measurement of the MCT is defined. The mathematical model of each measurement consists of the analytical formula (Equ. 1) of Wheatstone bridges:

$S_{i}=\frac{k_{S G}}{4} \cdot\left(\varepsilon_{1}-\varepsilon_{2}+\varepsilon_{3}-\varepsilon_{4}\right)=\frac{k_{S G}}{4} \cdot \bar{\varepsilon}_{a}$

The k-factor $k_{S G}$ is a strain gauge depending constant, which can vary for each strain gauge. The variation can be controlled by a calibration of the MCT. Nevertheless, the strain $\bar{\varepsilon}_{a}$ is effected by linearity deviation and hysteresis $\left(\varepsilon_{l h}\right)$, repeatability $\left(\varepsilon_{r p}\right)$, temperature influence $\left(\varepsilon_{T K}\right)$ as well as the crosstalk $\left(\varepsilon_{\text {talk }}\right)$ :

$\varepsilon_{\text {entire }}=\bar{\varepsilon}_{a}+\Delta \varepsilon_{\text {lh }}+\Delta \varepsilon_{r p}+\Delta \varepsilon_{T K}+\Delta \varepsilon_{\text {talk }}$

For the metrological uncertainty components of strain gauges, values from literature [9] and for the crosstalk the simulated effects are considered for the estimation of the measurement uncertainty (see Tab. 2). Additionally, probability density functions (PDF) for the uncertainty components are assumed to a uniform distribution except for the repeatability, which is assumed to a normal distribution. By knowing the crosstalk and the uncertainties of strange gauges, it is possible to estimate the expanded measurement uncertainty according to GUM [1]. With the distributions, the absolute standard uncertainty $u_{i}$ of each uncertainty component is calculated (Equ. (3)).

$u_{i}=c_{i} \cdot d_{i} \cdot F_{n o m, j}$

With the PDF factor $c_{i}$, which is the standard uncertainty of the chosen distribution and the relative uncertainty $d_{i}$ of the different uncertainty components.

Tab. 2: Relative uncertainty of strain gauges for linearity deviation and hysteresis $\left(d_{l h}\right)$, repeatability $\left(d_{r p}\right)$, temperature influence $\left(d_{T K}\right)$ [9] as well as the crosstalk $\left(d_{\text {talk }}\right)$

\begin{tabular}{|c|c|c|c|}
\hline & Value [\%] & $\begin{array}{c}\text { Referred } \\
\text { to }\end{array}$ & $\begin{array}{c}\text { PDF- } \\
\text { Factor }\end{array}$ \\
\hline$d_{l h}$ & 0,1 & $\begin{array}{c}F_{n o m, j} \\
\text { load }\end{array}$ & $c_{i}$ \\
\hline$d_{r p}$ & 0,01 & $\begin{array}{c}\text { Nominal } \\
\text { load }\end{array}$ & 1 \\
\hline$d_{T K}$ & 0,05 & $\begin{array}{c}\text { Nominal } \\
\text { load }\end{array}$ & 0,58 \\
\hline$d_{\text {talk }}$ & See Tab.1 & $\begin{array}{c}\text { Nominal } \\
\text { load }\end{array}$ & 0,58 \\
\hline
\end{tabular}

Afterwards the combined uncertainty is calculated out of the absolute standard uncertainties of the uncertainty components in respect to the mathematical model and the law of propagation of uncertainty (Equ. 4).

$u_{\text {total }}=\sqrt{\sum_{i=1}^{N}\left(\partial u_{i} / \partial i\right)^{2}}$

By taking a coverage probability of $95 \%(k=2)$ into account the absolute expanded measurement uncertainty is calculated after Equ. (5) (see Tab. 3).

$U_{\text {total }}=k \cdot u_{\text {total }}$

The relative expanded measurement uncertainty for each measurement is with $0.22 \%$ of the nominal load below the aimed requirement.

Tab. 3: Expanded measurement uncertainty for each measurement

\begin{tabular}{|c|c|c|c|}
\hline & $\begin{array}{c}\text { Nominal } \\
\text { load }\end{array}$ & $U_{\text {total }}$ & $U_{\text {total,rel }}$ \\
\hline$F_{x}$ & $1,5 \mathrm{MN}$ & $3,298 \mathrm{kN}$ & $\approx 0,22 \%$ \\
\hline$F_{y}$ & $2 \mathrm{MN}$ & $4,421 \mathrm{kN}$ & $\approx 0,22 \%$ \\
\hline$M_{x}$ & $5 \mathrm{MNm}$ & $10,933 \mathrm{kN}$ & $\approx 0,22 \%$ \\
\hline$M_{z}$ & $5 \mathrm{MNm}$ & $11,022 \mathrm{kN}$ & $\approx 0,22 \%$ \\
\hline
\end{tabular}




\section{Conclusion}

This paper shows the design study of a MCT for wind turbine test benches. The developed MCT shows a high potential for a precise measurement of all six DoF in its own individual measurement ranges. A first estimation of the measurement uncertainty shows that the expanded uncertainties are below $0.5 \%$ for all components. This includes the influence of crosstalk, temperature change as also the metrology characteristics like e.g. linearity, hysteresis and repeatability. In that way the MCT would provide a high potential to reduce the uncertainty in the traceability of the drive train behavior due to the applied loads.

Currently there is no possibility to calibrate such a MCT in the full measurement range, but with the upcoming $5 \mathrm{MN} \cdot \mathrm{m}$ torque standard measuring device (expected 2021) at the National German Metrology Institute (PTB) the basis is laid for a calibration according to metrological standards [10].

\section{Literature Reference}

[1] JCGM, "Evaluation of measurement Evaluation of measurement data - Guide to the expression of uncertainty in measurement", (2010)

[2] AGEB - AG Energiebilanzen e.V., "Bruttostromerzeugung in Deutschland ab 1990 nach Energieträgern", https://agenergiebilanzen.de/index.php?article_id=29\&file Name $=20181214$ brd_stromerzeugung19902018.pdf, accessed April 11, 2019

[3] Bundesministerium für Wirtschaft und Energie, 7. Energieforschungsprogramm der Bundesregierung: Innovationen für die Energiewende, (2018)

[4] D. Bosse, G. Jacobs, T. Duda, Capabilities of Wind Turbine Ground Testing, World Congress and Exhibition on Wind \& Renewable Energy, Berlin, Germany (2016)

[5] R. Averous, M. Stieneker, S. Kock, C. Andrei, A. Helmedag, W. De Doncker,K. Hameyer, G. Jacobs, A. Monti, Development of a 4 MW FullSize, PEDG 2015 IEEE 6th International Symposium on Power Electronics for Distributed Generation Systems, Aachen (2015); doi: 10.1109/JESTPE.2017.2667399

[6] Stefan Kock, Georg Jacobs, Dennis Bosse, Gisa Foyer, "Influence on MN·m torque measurement in multi-MW nacelle test benches", DEWEK 2017 13th German Wind Energy Conference, Bremen (2017)

[7] VDI - Verein Deutscher Ingenieure, "Methodik zum Entwickeln und Konstruieren technischer Systeme und Produkte", Vol. 03.100.40, No. 2221, Beuth Verlag GmbH, Berlin (1993)

[8] S. Kock; G. Jacobs; D. Bosse; F. Strangfeld, XXII World Congress of the International Measurement Confederation, (2018); doi: 10.1088/1742-6596/1065/4/042014

[9] R. Schwart, Kraft, Masse, Drehmoment. In: Gevatter, H.-J.; Grünhaupt, U. (Hrsg.):
Handbuch der Mess- und Automatisierungstechnik in der Produktion, 55-92 (2006)

[10] Dr. Prof. h. c. F. Härtig, PhysikalischTechnische Bundesanstalt, Abteilung 1: Mechanik und Akustik, Abteilungsbericht 2017, (2018) 